\title{
A tree of geese: A phylogenomic perspective on the evolutionary history of True Geese
}

\author{
Jente Ottenburghs ${ }^{\mathrm{a}, *}$, Hendrik-Jan Megens ${ }^{\mathrm{b}}$, Robert H.S. Kraus ${ }^{\mathrm{c}, \mathrm{d}}$, Ole Madsen ${ }^{\mathrm{b}}$, Pim van Hooft ${ }^{\mathrm{a}}$, \\ Sipke E. van Wieren ${ }^{\mathrm{a}}$, Richard P.M.A. Crooijmans ${ }^{\mathrm{b}}$, Ronald C. Ydenberg ${ }^{\mathrm{a}, \mathrm{e}}$, Martien A.M. Groenen ${ }^{\mathrm{b}}$, \\ Herbert H.T. Prins ${ }^{a}$ \\ ${ }^{a}$ Resource Ecology Group, Wageningen University, Droevendaalsesteeg 3a, 6708 PB Wageningen, The Netherlands \\ ${ }^{\mathrm{b}}$ Animal Breeding and Genomics Centre, Wageningen University, Droevendaalsesteeg 1a, 6708 PB Wageningen, The Netherlands \\ ${ }^{\mathrm{c}}$ Department of Biology, University of Konstanz, D-78457 Konstanz, Germany \\ ${ }^{\mathrm{d}}$ Department of Migration and Immuno-Ecology, Max Planck Institute for Ornithology, Am Obstberg 1, D-78315 Radolfzell, Germany \\ ${ }^{\mathrm{e}}$ Centre of Wildlife Ecology, Simon Fraser University, V5A 1S6 Burnaby, BC, Canada
}

Keywords:

Consensus

Concatenation

Gene tree

Hybridization

Incomplete lineage sorting

Species tree

\begin{abstract}
A B S T R A C T
Phylogenetic incongruence can be caused by analytical shortcomings or can be the result of biological processes, such as hybridization, incomplete lineage sorting and gene duplication. Differentiation between these causes of incongruence is essential to unravel complex speciation and diversification events. The phylogeny of the True Geese (tribe Anserini, Anatidae, Anseriformes) was, until now, con tentious, i.e., the phylogenetic relationships and the timing of divergence between the different goose species could not be fully resolved. We sequenced nineteen goose genomes (representing seventeen spe cies of which three subspecies of the Brent Goose, Branta bernicla) and used an exon based phylogenomic approach (41,736 exons, representing 5887 genes) to unravel the evolutionary history of this bird group. We thereby provide general guidance on the combination of whole genome evolutionary analyses and analytical tools for such cases where previous attempts to resolve the phylogenetic history of several taxa could not be unravelled. Identical topologies were obtained using either a concatenation (based upon an alignment of $6,630,626$ base pairs) or a coalescent based consensus method. Two major lineages, corre sponding to the genera Anser and Branta, were strongly supported. Within the Branta lineage, the White cheeked Geese form a well supported sub lineage that is sister to the Red breasted Goose (Branta ruficol lis). In addition, two main clades of Anser species could be identified, the White Geese and the Grey Geese. The results from the consensus method suggest that the diversification of the genus Anser is heavily influ enced by rapid speciation and by hybridization, which may explain the failure of previous studies to resolve the phylogenetic relationships within this genus. The majority of speciation events took place in the late Pliocene and early Pleistocene (between 4 and 2 million years ago), conceivably driven by a global cooling trend that led to the establishment of a circumpolar tundra belt and the emergence of tem perate grasslands. Our approach will be a fruitful strategy for resolving many other complex evolutionary histories at the level of genera, species, and subspecies.
\end{abstract}

\section{Introduction}

Incongruence between phylogenies generated from different sets of genetic and phenotypic data poses a significant challenge

Abbreviations: BDS, birth-death process with species sampling; bp, base pairs; $\mathrm{CI}$, confidence interval; cytb, cytochrome b; GTR, general time reversible; mtDNA, mitochondrial DNA; Mya, million years ago; ND2, NADH dehydrogenase 2.

* Corresponding author.

E-mail address: jente.ottenburghs@wur.nl (J. Ottenburghs). in evolutionary biology. Such incongruence can be caused by ana lytical shortcomings (Davalos et al., 2012; Rokas et al., 2003), such as issues with limited taxon sampling, unmet assumptions in the modelling of sequence evolution, and the choice of different opti mality criteria (Graybeal, 1998; Rokas et al., 2003; Yang et al., 1994). Phylogenetic incongruence can also be generated by biolog ical processes, such as hybridization, incomplete lineage sorting and gene duplication (Degnan and Rosenberg, 2009; Maddison, 1997; Pamilo and Nei, 1988). Differentiation between these causes 
of incongruence is essential to unravel complex speciation and diversification events.

Although phylogenetic incongruence compromises the estima tion of species trees, it can be a virtue for the evolutionary biolo gist, who attempts to better understand complex speciation events that are often obscured by rapid diversification and hybridization (Degnan and Rosenberg, 2009; Toews and Brelsford, 2012). Genomes are mosaics of many different gene his tories (Ellegren et al., 2012; Maddison, 1997; Payseur, 2010) that can be compared to deduce the species tree, while also gaining more insights into intricate events of the speciation process, such as hybridization episodes or bursts of rapid diversification (Innan and Watanabe, 2006). In addition, conflicting gene histories can also be used to infer population sizes and divergence times (Rannala and Yang, 2003; Wall, 2003). Analysing phylogenetic incongruence from a genomic perspective of diverse gene histories will lead to a more complete picture of the speciation process.

The occurrence of phylogenetic incongruence is a common and widespread phenomenon: analyses of different genes often lead to discordant gene trees (Rokas et al., 2003). Consequently, several methods have been developed to estimate the species tree from a collection of contrasting gene trees (Degnan and Rosenberg, 2009; Delsuc et al., 2005). In concatenation (or supermatrix) meth ods all sampled genes are concatenated and analysed as a single "supergene" (de Queiroz and Gatesy, 2007). Supertree methods, on the other hand, involve separate analyses of the sampled genes and subsequent integration of the resulting trees into a species tree (Bryant, 2003). Certain supertree methods incorporate the multi species coalescent model to estimate the species tree from a set of heterogeneous gene trees (Knowles, 2009). The multispecies coalescent model extends the classical coalescent (Kingman, 1980) to multiple populations and describes gene trees as indepen dent random variables generated from the coalescence process occurring along lineages of the species tree (Liu et al., 2015). A number of coalescent based methods have been developed to esti mate the species tree from multigene sequence data, including Bayesian (e.g., BUCKy, Ane et al., 2007; BEAST, Drummond et al., 2012) and likelihood approaches (e.g., STEM, Kubatko et al., 2009; STELLS, Wu, 2012). Coalescent based methods have been successfully implemented to disentangle the complex evolutionary history of several closely related bird species (Carling et al., 2010; Hung et al., 2012; Lavretsky et al., 2014).

The failure to unravel the phylogenetic relationships between goose species of the tribe Anserini (commonly referred to as True Geese, see Table 1 for a taxonomic overview of this tribe) can be attributed to high levels of phylogenetic incongruence (Ruokonen et al., 2000). Although there have been several studies delving into the phylogeography of particular goose species (Humphries et al., 2009; Jonker et al., 2013; Paxinos et al., 2002; Quinn, 1992; Ruokonen et al., 2005, 2008; Scribner et al., 2003; Volkovsky et al., 2013), the phylogenetic relationships between most species remained unclear. Until now, species level phylogenies were based either on morphology (Livezey, 1996), or mitochondrial markers (Donne Gousse et al., 2002; Gonzalez et al., 2009; Lee et al., 2008; Ruokonen et al., 2000). These approaches resulted in contra dicting topologies and different mitochondrial markers led to dif ferent phylogenetic reconstructions (Fig. 1). Phylogenetic incongruence is particularly apparent in the genus Anser. Although phylogenetic incongruence can be caused by hybridization and/or incomplete lineage sorting, all previous studies on goose phy logeny were based on mitochondrial DNA (mtDNA), which sug gests analytical issues as the most likely cause of these incongruences. One example of the discrepancies among previous studies involves the phylogenetic position of the Lesser White fronted Goose (Anser erythropus). Morphological analyses (Livezey, 1996) and some mitochondrial markers (cytb and ND2,
Table 1

Current taxonomy for the True Geese (tribe Anserini) based on Clements et al. (2015).

\begin{tabular}{|c|c|c|}
\hline English name & Scientific name & Subspecies \\
\hline \multicolumn{3}{|l|}{ Genus ANSER } \\
\hline Swan Goose & Anser cygnoides ${ }^{\mathrm{a}}$ & \\
\hline \multirow[t]{3}{*}{ Taiga Bean Goose } & Anser fabalis & A. f. fabalis ${ }^{\mathrm{a}}$ \\
\hline & & A. $f$. johanseni \\
\hline & & A. $f$. middendorffii \\
\hline \multirow[t]{2}{*}{ Tundra Bean Goose } & Anser serrirostris & A. serrirostris rossicus ${ }^{\mathrm{a}}$ \\
\hline & & A. serrirostris serrirostris \\
\hline \multirow[t]{2}{*}{ Pink-footed Goose } & Anser & \\
\hline & brachyrhynchus $^{\mathrm{a}}$ & \\
\hline \multirow{5}{*}{$\begin{array}{l}\text { Greater White-fronted } \\
\text { Goose }\end{array}$} & Anser albifrons & A. a. albifrons (Eurasian) ${ }^{\mathrm{a}}$ \\
\hline & & A. a. flavirostris (Greenland) \\
\hline & & A. a. gambeli (Western) \\
\hline & & A. a. frontalis (Western) \\
\hline & & A. a. elgasi (Tule) \\
\hline $\begin{array}{l}\text { Lesser White-fronted } \\
\text { Goose }\end{array}$ & Anser erythropus ${ }^{\mathrm{a}}$ & \\
\hline \multirow[t]{2}{*}{ Greylag Goose } & Anser anser & A. a. anser (European) $)^{\mathrm{a}}$ \\
\hline & & A. a. rubrirostris (Siberian) \\
\hline Bar-headed Goose & Anser indicus $^{\mathrm{a}}$ & \\
\hline Emperor Goose & Anser canagicus ${ }^{\mathrm{a}}$ & \\
\hline \multirow{2}{*}{ Snow Goose } & Anser caerulescens & A. c. caerulescens ${ }^{\mathrm{a}}$ \\
\hline & & A. c. atlantica \\
\hline Ross' Goose & Anser rossii ${ }^{\mathrm{a}}$ & \\
\hline \multicolumn{3}{|l|}{ Genus BRANTA } \\
\hline \multirow[t]{4}{*}{ Brent Goose } & Branta bernicla & B. b. bernicla (Dark-bellied) ${ }^{a}$ \\
\hline & & B. b. hrota (Pale-bellied or \\
\hline & & $\begin{array}{l}\text { Atlantic) } \\
\text { B. b. nigricans (Black) }\end{array}$ \\
\hline & & B. b. orientalis \\
\hline Barnacle Goose & Branta leucopsis ${ }^{\mathrm{a}}$ & \\
\hline \multirow[t]{4}{*}{ Cackling Goose } & Branta hutchinsii & B. h. leucopareia (Aleutian) \\
\hline & & B. h. hutchinsii (Richardson's) \\
\hline & & B. h. minima (Minima $)^{a}$ \\
\hline & & B. h. taverni (Taverner's) \\
\hline \multirow[t]{7}{*}{ Canada Goose } & Branta canadensis & B. c. moffitti \\
\hline & & B. c. maxima \\
\hline & & B. c. occidentalis \\
\hline & & B. c. fulva \\
\hline & & B. c. canadensis ${ }^{\mathrm{a}}$ \\
\hline & & B. c. interior \\
\hline & & B. c. parvipes \\
\hline Hawaiian Goose & $\begin{array}{l}\text { Branta } \\
\text { sandvicensis }^{\mathrm{a}}\end{array}$ & \\
\hline Red-breasted Goose & Branta ruficollis ${ }^{\mathrm{a}}$ & \\
\hline
\end{tabular}

Blood samples retrieved from this (sub)species.

Donne Gousse et al., 2002; Gonzalez et al., 2009) report a sister relationship with the Greater White fronted Goose (Anser alb ifrons), whereas studies using the mitochondrial control region (Lee et al., 2008; Ruokonen et al., 2000) place the Lesser White fronted Goose in a clade with Taiga Bean Goose (Anser fabalis) and Pink footed Goose (Anser brachyrhynchus).

In accordance with the lack of a well supported phylogeny, the timing of origin of the extant goose species is unknown too. Fossil evidence indicates that geese were present during the Miocene and Pliocene (Brodkorb, 1964) and several phylogeographic studies reported Pleistocene origins of certain goose subspecies (Avise et al., 1992; Shields, 1990; Van Wagner and Baker, 1990). More over, a mtDNA study of the genus Anser dated speciation events to the late Pliocene and early Pleistocene (Ruokonen et al., 2000). Based on the available evidence, we hypothesize that the diversifi cation of modern goose species was initiated in the Pliocene, accompanied by further diversification into distinct subspecies during the Pleistocene. Recent developments in divergence timing methods, that integrate both genomic data and fossil calibration points, can be applied to test this hypothesis (Parham et al., 2012).

The objectives of this study were threefold: (1) to unravel the phylogenetic relationships within the Anserini tribe using phyloge nomic tools for species tree estimation, (2) to assess the timing of 


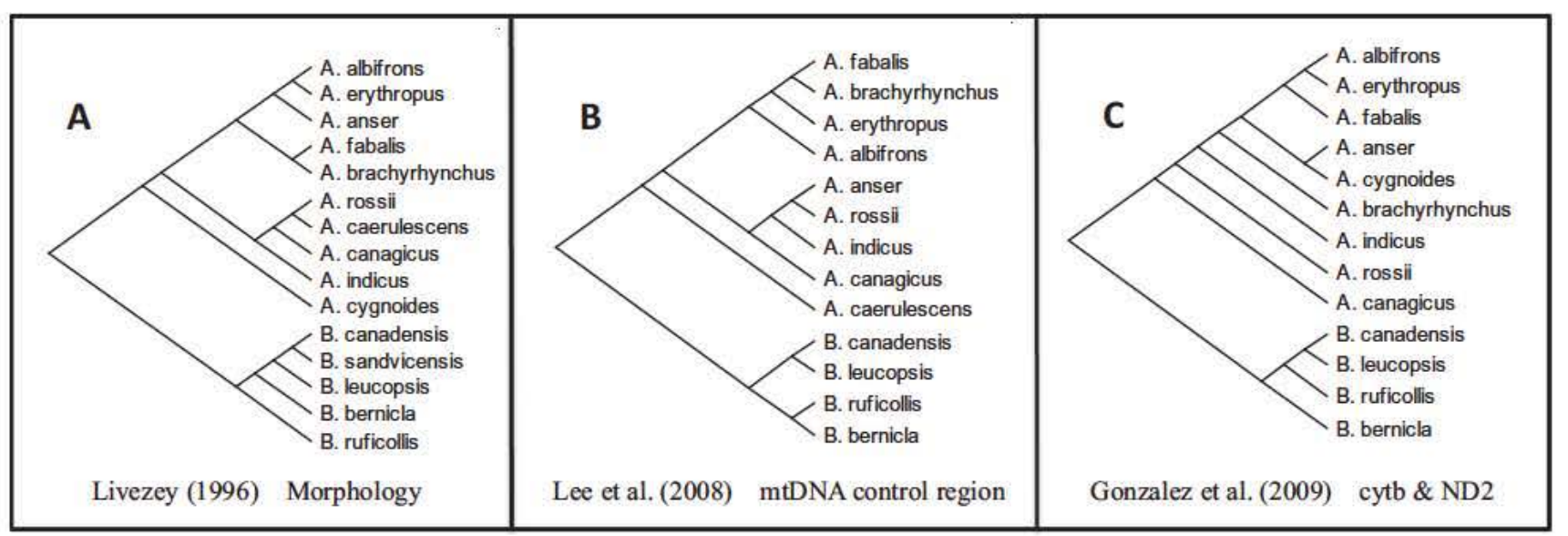

Fig. 1. Phylogenetic trees for the True Geese based on morphology or mitochondrial markers. (A) Morphology (Livezey, 1996). (B) Mitochondrial control region (Lee et al., 2008). (C) Cytochrome b and NADH hydrogenase 2 (Gonzalez et al., 2009).

divergence for the extant goose species by means of genomic and fossil data and (3) discuss these findings in a framework of ecolog ical, biogeographic and climatic events.

\section{Materials and methods}

\subsection{Sample collection and DNA extraction}

We collected blood samples from 19 goose (sub)species (Table 1 , see Table S1 for details). Genomic DNA was isolated from the blood samples using the Qiagen Gentra kit (Qiagen Inc.). Quality and quantity of the DNA was measured using the Qubit (Invitrogen, Life Technologies). Sequence libraries were made according to Illumina protocols and sequenced paired end $(100 \mathrm{bp})$ on the Hiseq2500 (Illumina Inc.).

\subsection{Processing sequences}

Paired end reads ( $100 \mathrm{bp}$ ) were mapped to the Mallard (Anas platyrhynchos) genome, version 73 (Huang et al., 2013, supplemen tary material) using SMALT (http://www.sanger.ac,uk/re sources/software/smalt/). Previous research indicated that SMALT is appropriate for mapping paired end reads when the reference genome is distantly related to the sampled species (Frantz et al., 2013). Furthermore, preliminary analyses showed that this soft ware produces the best results compared to other mapping soft ware (Fig. S2). SMALT uses a hash index of short words, sampled at equidistant steps along the reference genome. We applied default settings (word length $=13$, spacing of hashed words $=6$ ). Over $99 \%$ of the reads were mapped successfully in all samples, but to decrease the incidence of off site mapping we only accepted properly mapped paired reads, resulting in mapping rates between $63 \%$ and $78 \%$ (Table S2). From the resulting bam files duplicate sequences were excluded using SAMtools dedup and realigned with IndelRealigner in GATK 2.6. Variant sites were called by means of the UnifiedGenotyper in GATK 2.6 with a minimum base quality of 20 and a heterozygosity value of 0.01 (this value has pro ven to be suitable for variant calling after mapping to a distantly related reference genome, see Frantz, 2015). The genomic positions of exonic sequences that were one to one orthologous between the Mallard and other bird species (chicken, turkey, flycatcher and zebra finch) were retrieved from the ENSEMBL data base. These genomic positions were used to extract the sequences from the different goose genomes. A final set of 41,736 unique exons (representing 5887 genes) were concatenated, resulting in an alignment of $6,630,626$ base pairs (bp).

Paired end reads ( $100 \mathrm{bp}$ ) were also mapped to the Swan Goose (Anser cygnoides) genome (Lu et al., 2015) using BWA (Li and Durbin, 2009). Over $95 \%$ of the reads were mapped successfully for all species. However, mapping to the genome of a species that is included in the phylogenetic analysis (in this case the Swan Goose) potentially leads to an inherent bias that could interfere with the phylogenetic analysis. For instance, mean mapping qual ity (Fig. S2) is higher for species belonging to the same genus (Anser) as the reference genome compared to species of the other genus (Branta). Therefore we decided to use the variant calls based on the mapped reads to a more distantly related reference genome, the Mallard ( $A$. platyrhynchos). Although this choice leads to a reduction in the amount of data, it avoids the bias introduced by mapping to the Swan Goose genome, because all species are equally distantly related to the Mallard. A similar approach has been used to reconstruct the phylogeny of Cichlid fish (Ilves and Lopez Fernandez, 2014).

\subsection{Phylogenomic analyses}

We applied several phylogenomic methods based on maximum likelihood implemented in RAxML 8.3 (Stamatakis, 2006). We used both supertree and supermatrix techniques (Delsuc et al., 2005). First, the concatenated alignment was analysed under two com monly used substitution models (GTR $+\Gamma$ and $G T R+\Gamma+I)$, both with 100 bootstrap replications (Ranwez et al., 2007). Second, we selected 3570 one to one orthologous genes (thus combining the gene exons) with a minimum length of $500 \mathrm{bp}$. These genes were analysed separately under a GTR $+\Gamma$ substitution model with 100 rapid bootstraps. The resulting gene trees were filtered on average bootstrap support (minimum $>50$ ). This final set of 3558 well supported gene trees was consequently combined into a con sensus tree using the software package STELLS version 1.6.1 (Wu, 2012). STELLS infers the species tree from a given set of gene trees, using the multispecies coalescent as underlying genealogical pro cess. To assess support for particular clades in the supertree anal ysis, concordance factors were calculated in DensiTree (Bouckaert, 2010). A concordance factor represents the percentage of gene trees that contain the same node as the species tree (Baum, 2007; Knowles and Kubatko, 2010). Trees were rooted either by using an outgroup (Mallard), or by midpoint rooting (without an outgroup). Both methods resulted in the same position of the root in the tree. Here, we present the results of the midpoint rooting 
only because the high divergence of the root species (Mallard) resulted in conflicting parameter estimations in RAxML 8.3.

\subsection{Molecular clock analyses}

Ideally, a molecular clock analysis is run with multiple calibra tion points (fossils or biogeographic events) using a relaxed clock (Parham et al., 2012). Unfortunately, the fossil record for geese is too sparse to use multiple calibration points (see Section 4). There fore, we followed the method outlined below. The resulting diver gence times should thus not be interpreted as the exact dates of divergence, but rather as rough guiding estimates that allow us to formulate testable hypotheses on the biogeographical and eco logical drivers of goose speciation.

We estimated divergence times using an approximate likeli hood method as implemented in MCMCtree (in PAML version 4, Yang, 2007), with a global clock and birth death sampling. We fit ted a GTR $+\Gamma$ model to the concatenated alignment and estimated a mean substitution rate by fitting a strict clock and setting the root age at 9 Mya based on previous studies (Fulton et al., 2012; Jetz et al., 2012). This mean substitution rate $(0.134992 \pm$ 0.000307 substitutions/site/Myr) was used to adjust the prior on the substitution rate (rgene) modelled by a $\Gamma$ distribution as $\Gamma$ $(1,7.4)$. Parameters for the birth death process with species sam pling (BDS) and $\sigma^{2}$ values were set at 110 and $G(1,10)$, respec tively. The Anser Branta divergence was constrained between 20 and 4 million years ago to reflect reports of goose fossils in this time period (Brodkorb, 1964). MCMCtree analyses were run multi ple times to check for convergence of results. Analyses with a relaxed clock gave similar results compared to the global clock approach, but without convergence of results. Therefore, we only present the estimates of the global clock analysis here. To further assess the reliability of the MCMCtree analysis, we performed a global clock calculation of divergence times using the software package PATHd8 (Britton et al., 2007), setting the root age at 9.5 Mya as a result of the MCMCtree analysis.

\section{Results}

The concatenation and consensus methods resulted in identical topologies (Fig. 2). All clades in the concatenation analysis were supported by maximum bootstrap values, except for the sister species relation between Tundra Bean Goose and Pink footed Goose which has a bootstrap support of 95 . Analyses with the GTR $+\Gamma$ substitution model and the GTR $+\Gamma+$ I substitution model resulted in the same topology. There is a clear separation between the two genera (Anser and Branta). The genus Branta consists of a clade of White cheeked Geese Canada Goose (Branta canadensis), Cackling Goose (Branta hutchinsii), Barnacle Goose (Branta leucop sis) and Hawaiian Goose (Branta sandvicensis) and two basal splits

leading to Brent Goose (Branta bernicla) and Red breasted Goose (Branta ruficollis). The most basal split in the genus Anser leads to the Bar headed Goose (Anser indicus). Next, two main clades can be recognised: the White Geese Snow Goose (Anser caerulescens), Ross' Goose (Anser rossii) and Emperor Goose (Anser canagicus) and the Grey Geese Greylag Goose (Anser anser), Swan Goose (A. cygnoides), the White fronted Geese (A. albifrons and A. erythro pus) and the Bean Goose complex (A. fabalis, Anser serrirostris and $A$. brachyrhynchus). Concordance factors ranged between $4 \%$ and $93 \%$ (Fig. 2), with generally higher values found within Branta (30 93\%) than within Anser ( 4 54\%). Indeed, concordance factors in the con sensus analysis were consistently higher for the Branta compared to the Anser (Mann Whitney $U=60.5, p=0.015$ ), which indicates higher levels of phylogenetic incongruence in the latter clade.
Fig. 3 gives an overview of the divergence times (with 95\% CI) for the different speciation events. The split between Anser and Branta was estimated at 9.5 Mya (15.1 4.2). This estimate was used for root calibration in the PATHd8 analysis, which resulted in similar divergence times compared to the MCMCtree analysis $\left(R^{2}=0.973, p<0.001\right.$, Fig. S3). Most mean divergence times are concentrated in between 4 and 2 Mya. The mean divergence times for Red breasted Goose (B. ruficollis) and Brent Goose (B. bernicla) are dated to approximately 6.8 and 5.8 Mya, respectively. Finally, three Brent Goose subspecies (bernicla, hrota and nigricans) origi nated during the Pleistocene, around one Mya. An overview of the evolutionary history of True Geese is presented in Fig. 4, com bining phylogenetic relationships, divergence times and current distributions.

\section{Discussion}

Whole genome analyses have recently been used to unravel the phylogenetic relations between the major bird orders (Jarvis et al., 2014; Prum et al., 2015), but our study presents one of the first phylogenomic analyses of a group of closely related bird species (DaCosta and Sorenson, 2016; Nater et al., 2015). As both concate nation and consensus methods resulted in the same topology and all nodes on the concatenation tree are supported by high boot strap values, it is likely that the resulting phylogeny closely approaches the actual species tree for the Anserini. We firmly resolve several incongruences among previous studies (see Section 4.1).

The resolution of these incongruences can be attributed to the deliberately exon based phylogenomic approach in our study (Ilves and Lopez Fernandez, 2014). First, the choice of one to one orthologous exonic sequences ensures high mapping quality because of greater sequence conservation of exons compared to introns (Kerr et al., 2014; Ranwez et al., 2007). Moreover, the use of one to one orthologous sequences avoids the analytical com plexities introduced by duplicated genes (Maddison, 1997) and the occurrence of indels and greater sequence divergence that can pose substantial problems during multiple sequence alignment (Liu et al., 2010). Second, the genome wide set of thousands of genes enabled us to deduce with high statistical power the species tree despite potentially high levels of phylogenetic incongruence caused by incomplete lineage sorting and/or hybridization. Indeed, both the concatenation and the consensus method uncovered the same phylogenetic signal from the genome wide sequence data. Furthermore, the concordance factors calculated in the coalescent based consensus method provide important insights into the effects of incomplete lineage sorting and/or hybridization in certain clades.

\subsection{Phylogenetic relationships}

Monophyly of the genera Anser and Branta was already well established (Delacour and Mayr, 1945). However, the timing of separation of these genera is still a matter of debate. Fossil evi dence suggested that these two groups of geese have a common ancestor between 5 and 4 Mya (Brodkorb, 1964; Wetmore, 1956), and this date has been used to calibrate the molecular clock in birds (Shields and Wilson, 1987). The consistency of this molecular clock has been questioned (van Tuinen and Hedges, 2001; Weir and Schluter, 2008), because subsequent molecular studies reported older dates for the Anser Branta split ranging from 23 to 9 million years ago (Brown et al., 2008; Fulton et al., 2012; Gonzalez et al., 2009; Jetz et al., 2012; Jiang et al., 2010; Pereira and Baker, 2006). We decided to use 9 million years to calibrate the mutation rate, based on recent estimates (Fulton et al., 2012; 


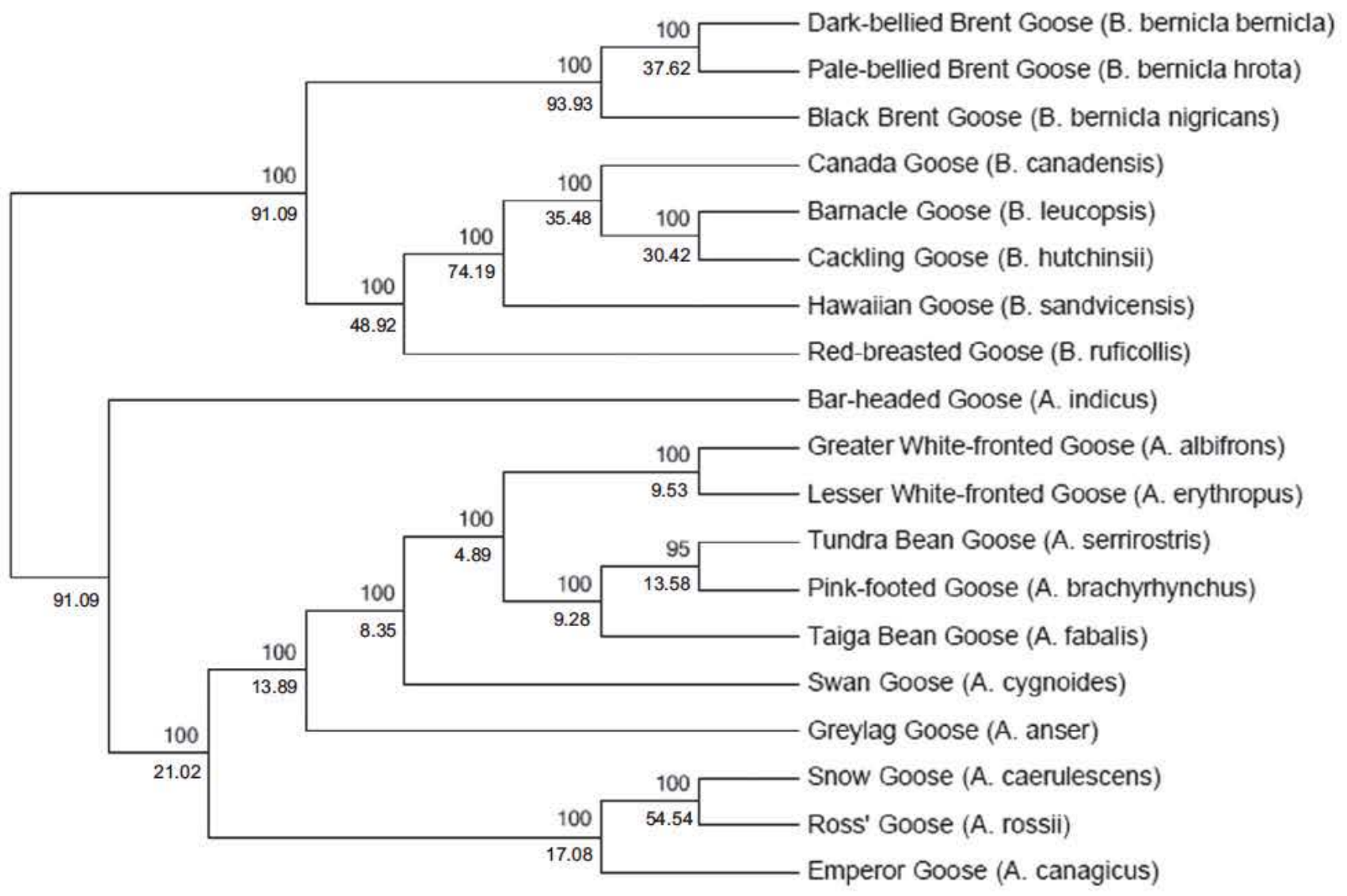

Fig. 2. Maximum Likelihood Tree for the True Geese based on consensus and concatenation methods. Bootstrap values of the concatenation analysis above branches, concordance factors of the consensus analysis below.

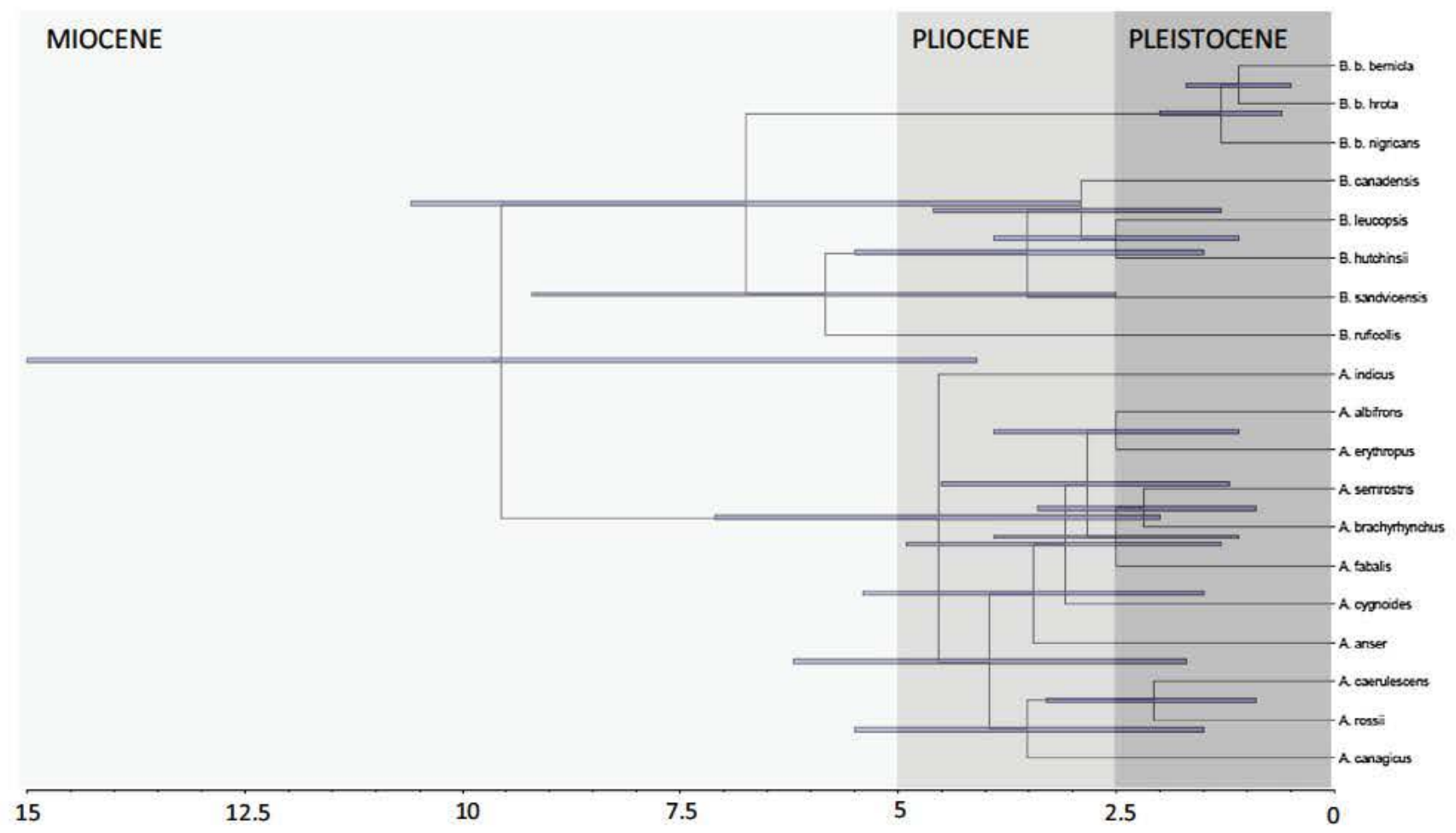

Fig. 3. Timed phylogenetic tree using a global clock approach in MCMCtree. Blue bars indicate $95 \%$ confidence intervals. 
A

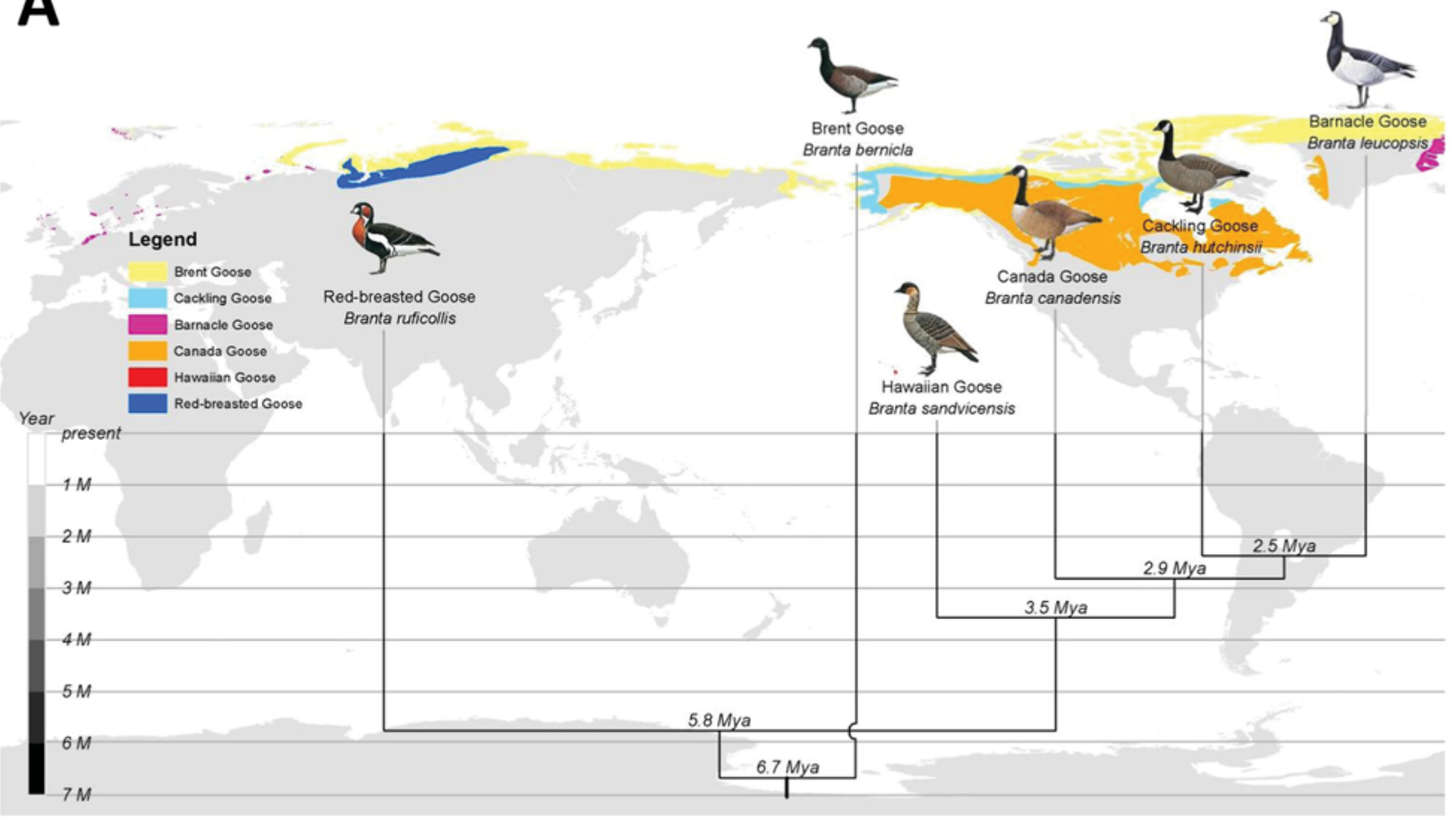

B

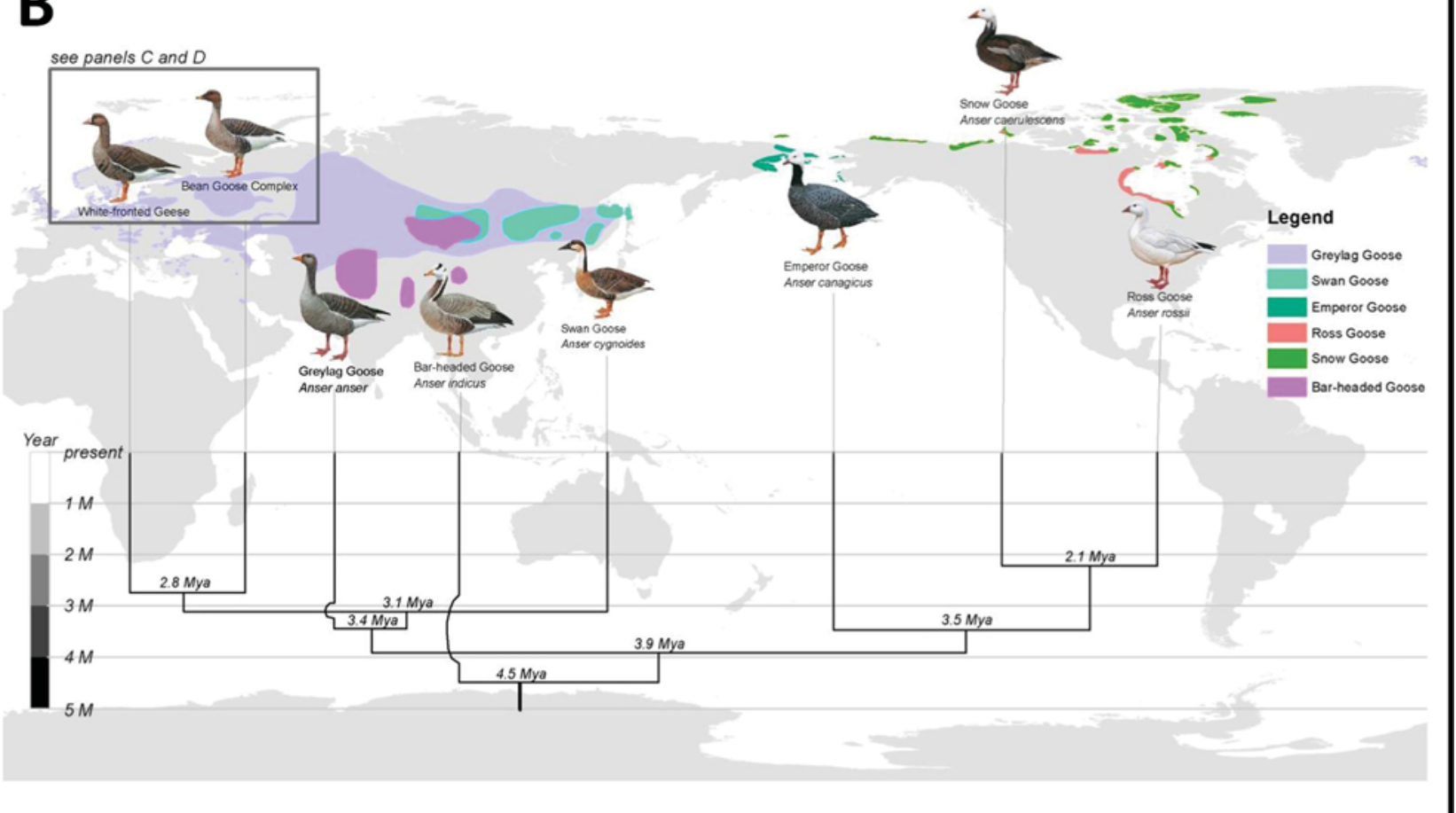

Fig. 4. An overview of the evolutionary history of the True Geese combining phylogenetic tree, divergence times and current distributions of all species. Distributions based on BirdLife's species range maps. Drawings used with permission of the Handbook of Birds of the World.

Jetz et al., 2012). Moreover, we used a fossil constraint between 20 and 4 million years ago to reflect reports of goose fossils in this time period (Brodkorb, 1964). The resulting wide confidence inter val for the Anser Branta split in our molecular clock analysis, rang ing from 15.1 to 4.2 Mya, indicates that there is still considerable uncertainty for this estimate. This uncertainty is a consequence of the lack of proper fossil calibration points for the Anserini tribe. Although there are numerous goose fossils (Brodkorb, 1964), it is not possible to confidently determine the phylogenetic position of these fossils. A thorough phylogenetic analysis of goose fossils, 


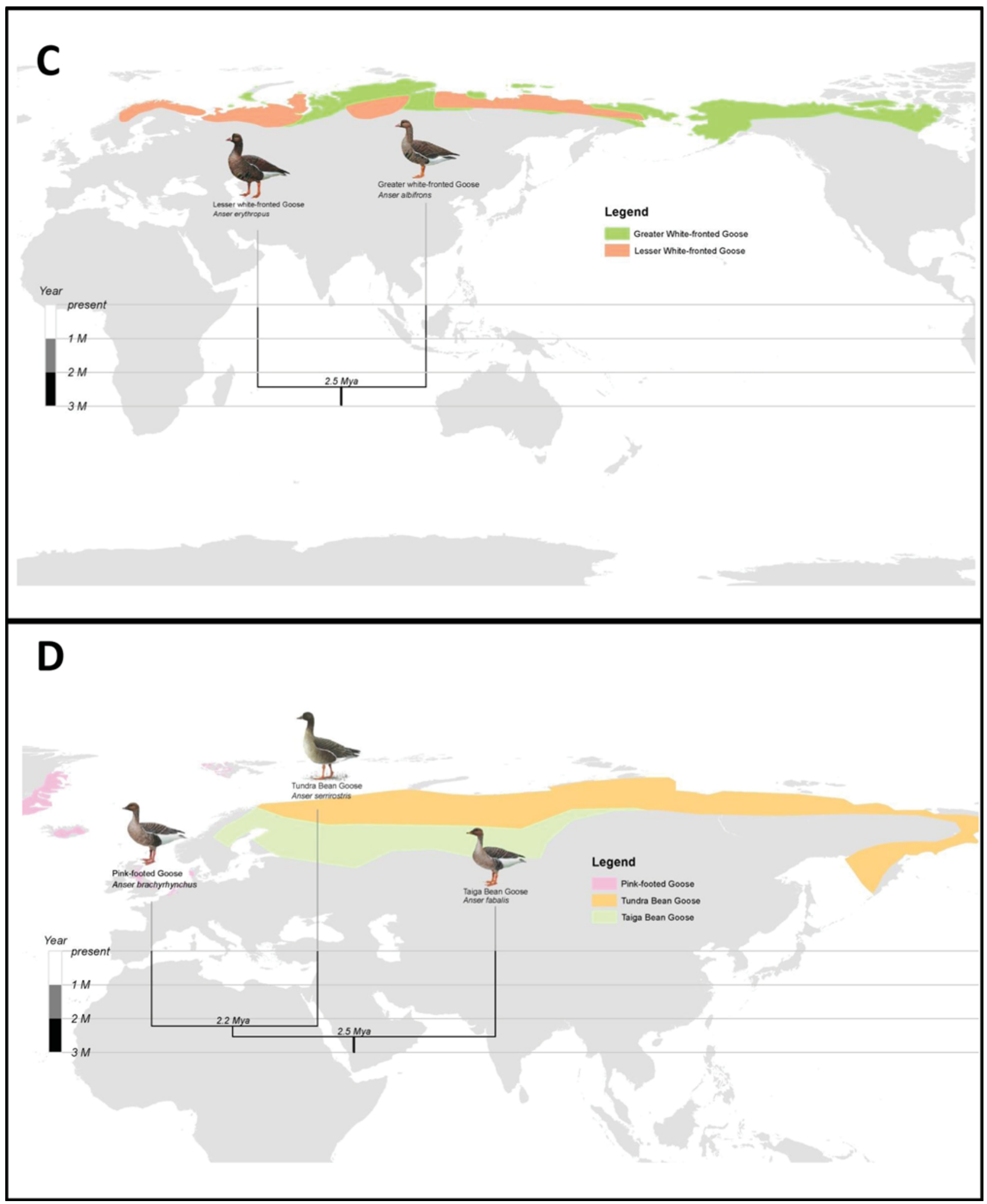

Fig. 4 (continued)

such as the one recently published for the Charadriiformes (Smith, 2015), is clearly essential in order to achieve better estimates for the divergence times.

Phylogenetic relationships within the genus Branta (commonly referred to as the Black Geese) could be unambiguously inferred, consisting of a clade of White cheeked Geese Canada Goose ( $B$. canadensis), Cackling Goose (B. hutchinsii), Barnacle Goose (B. leu copsis) and Hawaiian Goose (B. sandvicensis) and two basal splits leading to Brent Goose (B. bernicla) and Red breasted Goose ( $B$. ruficollis). The exact phylogenetic position of the latter two species 
remained uncertain up to our study: some studies reported a sister species relation (Lee et al., 2008; Paxinos et al., 2002), while others placed either Red breasted Goose (Donne Gousse et al., 2002; Livezey, 1996) or Brent Goose at the base of the Branta clade (Gonzalez et al., 2009). We find strong support for a basal split leading to the Brent Goose in Branta. Within the White cheeked Geese clade there is a clear distinction between Canada Goose and Cackling Goose which were considered large and small bodied forms of the same species in the past (Owen, 1980). The sig nificant morphological and molecular divergence between these species reported in previous studies is therefore confirmed by our genomic analysis (Scribner et al., 2003; Van Wagner and Baker, 1990). In addition, we find support for the sister species relation between Cackling Goose and Barnacle Goose described previously (Paxinos et al., 2002).

The Hawaiian Goose was the first species to split from the White cheeked Geese clade, around 3.5 Mya (5.5 1.5). This date suggests that the ancestors of the Hawaiian Goose arrived on islands that were present in this time period, such as Kauai, Nihoa or Oahu, (Macdonald et al., 1983). However, it is also possible that the divergence of the Hawaiian Goose occurred on the mainland, followed by colonization of Hawaii at a later stage. Our results con trast with the findings of Paxinos et al. (2002), who reconstructed the evolutionary history of the Hawaiian goose radiation (i.e. the modern Hawaiian Goose and several extinct species) using mtDNA extracted from fossil remains. They found that the Hawaiian radi ation is a sister group to the Canada Goose that diverged approxi mately 890,000 years ago (1.3 Mya 577,000$)$, a date also reported by Quinn et al. (1991) based on restriction fragments of mtDNA. The incongruence between our analysis and those of Paxinos et al. (2002) and Quinn et al. (1991) is probably the result of incomplete lineage sorting. A closer look at the results of the con sensus method (which takes into account incomplete lineage sort ing) supports this explanation. The clade comprising Canada Goose, Cackling Goose and Barnacle Goose is recovered in 35.5\% of the gene trees, whereas a sister relation between Canada Goose and Hawaiian Goose is supported by $16 \%$ of the gene trees. Gene tree incongruence can also be the result of hybridization (Maddison, 1997), but this is less likely as the Hawaiian Goose has been geographically isolated from the Canada Goose. However, we cannot rule out the possibility that vagrant Canada Geese might have reached the Hawaiian archipelago in the past (Berger, 1972) or that Canada Geese and Hawaiian Geese have hybridized before the colonization of Hawaii. Another incongruence between our results and those of Paxinos et al. (2002) and Quinn et al. (1991) concerns the timing of divergence of the Hawaiian Goose (3.5 Mya versus 890,000 years ago). This large difference can be explained by the fossil calibration used by these studies as they both calibrated the molecular clock by setting the date of the Anser Branta split at $4.5 \mathrm{Mya}$, which is later than the date we use here (9.5 Mya). In addition, the effective population size of mtDNA is smaller compared to nuclear DNA, which results in a consider ably younger divergence time (Ballard and Whitlock, 2004). There fore the Hawaiian Goose most likely diverged earlier than expected, before the further diversification of the white cheeked goose ancestor that gave rise to the Canada Goose, Cackling Goose and Barnacle Goose.

In contrast to Branta, the phylogenetic relationships within the genus Anser were largely unresolved up to this study. The failure to reconstruct the evolutionary history of this bird group can be attributed to rapid speciation, which results in incomplete lineage sorting, and hybridization (Ruokonen et al., 2000). Indeed, concor dance factors in the consensus analysis were lower for the Anser clade compared to the Branta clade, indicating higher levels of gene tree discordance in the former clade. By using genomic data and methods that take into account gene tree discordance, we were able to construct a well supported phylogeny for the genus Anser. The most basal split leads to the morphologically divergent Bar headed Goose (A. indicus). Next, two main clades can be recog nised: the White Geese Snow Goose (A. caerulescens), Ross' Goose (A. rossii) and Emperor Goose (A. canagicus) that are sometimes placed in a separate genus, Chen (Gil and Donsker, 2013), and the Grey Geese Greylag Goose (A. anser), Swan Goose (A. cygnoides), the White fronted Geese (A. albifrons and A. erythropus) and the Bean Goose complex (A. fabalis, $A$. serrirostris and $A$. brachyrhynchus).

The monophyly of the White Geese was already well established from a morphological perspective (Livezey, 1996), but molecular analyses were unable to recover this clade (Donne Gousse et al., 2002; Gonzalez et al., 2009; Lee et al., 2008; Paxinos et al., 2002). We were able to confirm the mono phyly of this clade, although gene tree discordance was apparent in the consensus method as only $17.1 \%$ of the gene trees supported this clade. From a taxonomic point of view the White Geese should be classified in the genus Anser, because placing them in the dis tinct genus Chen results in polyphyly of the genus Anser.

Within the Grey Geese clade, the position of the Swan Goose, as a sister species to the White fronted Geese and the Bean Goose complex, is quite surprising. Given its morphological disparity, the Swan Goose was traditionally placed at the base in the Grey Geese clade (Livezey, 1996) and has even been classified in a sep arate genus, Cygnopis (Owen, 1980). Also, the phylogenetic position of the Lesser White fronted Goose has been established as a sister species of the Greater White fronted Goose. The placement of the Lesser White fronted Goose in a clade with Taiga Bean Goose and Pink footed Goose by previous studies can be explained by analytical shortcomings, incomplete lineage sorting and/or hybridization (Lee et al., 2008; Ruokonen et al., 2000).

The taxonomy and evolutionary relationships of the Bean Goose complex have been controversial (Delacour, 1951; Mooij and Zöckler, 1999; Sangster and Oreel, 1996). The current classification encompasses three species: the Pink footed Goose, the Taiga Bean Goose (three subspecies) and the Tundra Bean Goose (two sub species). However, based on analyses of the mitochondrial control region, Ruokonen et al. (2008) identified three distinct lineages: the Pink footed Goose, the Middendorff's Goose (currently a sub species of Taiga Bean Goose), and the Bean Goose (currently split in Taiga and Tundra Bean Goose). We report a sister species rela tion between Pink footed Goose and Tundra Bean Goose. The phy logenetic relationships in this complex are highly influenced by incomplete lineage sorting and/or hybridization. A thorough geno mic analysis in a phylogeographic context with broad sampling across the entire range of this species group is needed to confi dently reconstruct the evolutionary history of the Bean Goose complex.

\subsection{Biogeography and ecology}

It can be conceived that True Geese originated in Eurasia, con sidering the fact that the earliest (Miocene) goose fossils have been excavated in Western Europe (Brodkorb, 1964) and species at the phylogenetically most basal splits (Bar headed Goose, Brent Goose and Red breasted Goose) currently have a largely Eurasian distri bution (although the current distribution does not necessarily coincide with the past distribution). If we assume a Eurasian origin, at least three colonization events to North America can be recog nized: by the White cheeked Geese, by the White Geese, and finally by the Greater White fronted Geese. However, this scenario remains to be tested by means of ancestral reconstructions in com bination with fossil data. Based on the phylogeny and present day biogeographic patterns, we can recognize three main groups: the Black Geese (Branta) with members in North America and Eurasia, 
the Grey Geese (Anser) with a largely Eurasian distribution, and the North American White Geese (Anser).

Within these three groups, there is substantial variation in beak morphology which is most pronounced in the Grey Geese of the genus Anser. The Grey Geese can be regarded as an adaptive radi ation, because they show "the evolution of ecological and pheno typic diversity within a rapidly multiplying lineage" (Schluter, 2000). To qualify as an adaptive radiation, four criteria should be met: (1) common ancestry, (2) rapid speciation, (3) phenotype environment correlation, and (4) trait utility (Schluter, 2000). The first two criteria (common ancestry and rapid speciation) are sup ported by our phylogenomic analyses. All members of the Grey Geese share a common ancestor around 3.4 Mya and diversified into several distinct species over a period of about one million years. A phenotype environment correlation indicates that differ ences in phenotypes are associated with the use of different resources or environments. For geese, this correlation has been confirmed by numerous field studies (Carriere et al., 1999; Fox and Bergersen, 2005; Giroux and Bergeron, 1996). For instance, the Taiga Bean Goose has a long thin bill adapted for probing soft substrates of bogs and marshlands to feed on underground plant material, whereas the Pink footed Goose has a short bill suitable for grazing and seed stripping (Owen, 1976; Reed, 1976). Finally, the trait utility (i.e., evidence that morphological or physiological traits are indeed useful when used in the associated environment) of beak morphology in geese has been confirmed experimentally (Durant et al., 2003; Heuermann et al., 2011; Zhang et al., 2015). The Grey Geese can thus be regarded as an adaptive radiation in terms of beak morphology.

The diversification in beak morphology is less pronounced in the Black Geese and White Geese, which can be attributed to the fact that some members of the Black Geese (specifically, the White cheeked Geese) and the White Geese coexisted in North America and consequently affected each other in terms of beak morphology evolution by means of resource competition and con sequent character displacement (Dayan and Simberloff, 2005; Schluter, 2000). So, while the Eurasian niches were rapidly filled by members of one ancestral Grey Goose lineage, the North Amer ican niches were filled by members of two distantly related lin eages: the Black Geese and the White Geese. One can see every North American species as the ecological equivalent of a Eurasian species (or vice versa), for example, Owen (1980) remarked that "the larger races of the Bean Goose [are] the Canada's [goose] eco logical counterpart in Eurasia." However, it is also possible that the Black Geese and White Geese both exhibited an adaptive radiation in North America comparable with the Eurasian radiation of the Grey Geese, but that several species went extinct during the Pleis tocene (Martin and Klein, 1989).

We hypothesized a Pliocene origin for modern goose species followed by diversification at the subspecies level during the Pleis tocene, based on the available fossil evidence (Brodkorb, 1964) and previous molecular studies (Avise et al., 1992; Ruokonen et al., 2000; Scribner et al., 2003; Van Wagner and Baker, 1990). Indeed, our analysis indicates that the majority of speciation events took place at the end of the Pliocene. The approximate date of diversifi cation coincides with the beginning of a period of climatic oscilla tions between 3.2 and 1.9 million years ago. This period was part of a fast global cooling trend, following the closure of the Panama Seaway and the uplifting of the Tibetan Plateau around four million years ago (Zachos et al., 2001). This resulted in the formation of permanent Northern Hemisphere ice sheets, the establishment of a circumpolar tundra belt and the emergence of temperate grass lands, which opened up new ecological niches in which new groups of animals and plants were able to spread (Kahlke, 2014; Prins, 1998). The tundra habitat serves as breeding ground for geese (Owen, 1980), while the temperate grasslands act as winter ing grounds where mate choice takes place (Rodway, 2007). More over, these tundra and grassland habitats provided ample opportunity for geese to explore new ecological niches and diver sify in beak morphology.

\section{Conclusions}

Using a phylogenomic approach we were able to resolve the contentious phylogenetic history of the True Geese. Furthermore, taking advantage of the many contrasting gene histories, we gained more insight into the effects of complex speciation pro cesses, such as rapid diversification and hybridization, in certain clades. The relative importance of hybridization in the evolution ary history of the True Geese remains to be investigated. The wide spread occurrence of hybridization in birds (Ottenburghs et al. 2015), and specifically waterfowl (Kraus et al., 2012; Randler, 2008; Ottenburghs et al., 2016), suggests that hybridization can act as an important component in avian speciation (Rheindt and Edwards, 2011). By integrating over the full exon set of genes we made a first step to quantitatively describe both species and gene histories. Our approach will be a fruitful strategy for resolving many other complex evolutionary histories at the level of genera, species, and subspecies.

\section{Acknowledgments}

We thank three anonymous reviewers for their comments on the previous version of this manuscript. We are indebted to Gerard Müskens, Jurre Brenders, Henk en Wim Meinen, Ouwehands Zoo (Gerard Meijer), Avifauna (Jan Harteman \& Joost Lammers) and the Nederlands Instituut voor Ecologie (NIOO KNAW) for their help during the collection of blood samples, and to Kimberley Laport for the DNA extraction. We thank Laurent Frantz and Joost de Jong for valuable discussions and Audrie Siahainenia for the preparation of Fig. 4. This research was funded by Stichting de Eik.

\section{Appendix A. Supplementary material}

Supplementary data associated with this article can be found, in the online version, at http://dx.doi.org/10.1016/j.ympev.2016.05. 021.

\section{References}

Ane, C., Larget, B., Baum, D.A., Smith, S.D., Rokas, A., 2007. Bayesian estimation of concordance among gene trees. Mol. Biol. Evol. 24, 412-426.

Avise, J.C., Alisauskas, R.T., Nelson, W.S., Ankney, C.D., 1992. Matriarchal population genetic-structure in an avian species with female natal philopatry. Evolution 46, 1084-1096.

Ballard, J.W.O., Whitlock, M.C., 2004. The incomplete natural history of mitochondria. Mol. Ecol. 13, 729-744.

Baum, D.A., 2007. Concordance trees, concordance factors, and the exploration of reticulate genealogy. Taxon 56, 417-426.

Berger, A.J., 1972. Hawaiian birdlife.

Bouckaert, R.R., 2010. DensiTree: making sense of sets of phylogenetic trees. Bioinformatics 26, 1372-1373.

Britton, T., Anderson, C.L., Jacquet, D., Lundqvist, S., Bremer, K., 2007. Estimating divergence times in large phylogenetic trees. Syst. Biol. 56, 741-752.

Brodkorb, P., 1964. Catalogue of Fossil Birds: Part 2 (Anseriformes through Galliformes). University of Florida.

Brown, J.W., Rest, J.S., Garcia-Moreno, J., Sorenson, M.D., Mindell, D.P., 2008. Strong mitochondrial DNA support for a Cretaceous origin of modern avian lineages. BMC Biol., 6

Bryant, D., 2003. A classification of consensus methods for phylogenetics. DIMACS Series Discr. Math. Theor. Comput. Sci. 61, 163-184.

Carling, M.D., Lovette, I.J., Brumfield, R.T., 2010. Historical divergence and gene flow: coalescent analyses of mitochondrial, autosomal and sex-linked loci in passerina buntings. Evolution 64, 1762-1772.

Carriere, S., Bromley, R.G., Gauthier, G., 1999. Comparative spring habitat and food use by two arctic nesting geese. Wilson Bull. 111, 166-180.

Clements, J.F., Schulenberg, T.S., Iliff, M.J., Roberson, D., Fredericks, T.A., Sullivan, B. L., Wood., C.L., 2015. The eBird/Clements checklist of birds of the world: 
v2015. Downloaded from < http://www.birds.cornell.edu/clementschecklist/ download/>.

DaCosta, J.M., Sorenson, M.D., 2016. DdRAD-seq phylogenetics based on nucleotide, indel, and presence-absence polymorphisms: analyses of two avian genera with contrasting histories. Mol. Phylogenet. Evol. 94, 122-135.

Davalos, L.M., Cirranello, A.L., Geisler, J.H., Simmons, N.B., 2012. Understanding phylogenetic incongruence: lessons from phyllostomid bats. Biol. Rev. 87, 9911024.

Dayan, T., Simberloff, D., 2005. Ecological and community-wide character displacement: the next generation. Ecol. Lett. 8, 875-894.

de Queiroz, A., Gatesy, J., 2007. The supermatrix approach to systematics. Trends Ecol. Evol. 22, 34-41.

Degnan, J.H., Rosenberg, N.A., 2009. Gene tree discordance, phylogenetic inference and the multispecies coalescent. Trends Ecol. Evol. 24, 332-340.

Delacour, J., 1951. Taxonomic notes on the bean geese, Anser fabalis Lath. Ardea 39, 135-142.

Delacour, J., Mayr, E., 1945. The family Anatidae. Wilson Bull., 3-55

Delsuc, F., Brinkmann, H., Philippe, H., 2005. Phylogenomics and the reconstruction of the tree of life. Nat. Rev. Genet. 6, 361-375.

Donne-Gousse, C., Laudet, V., Hanni, C., 2002. A molecular phylogeny of anseriformes based on mitochondrial DNA analysis. Mol. Phylogenet. Evol. 23, 339-356.

Drummond, A.J., Suchard, M.A., Xie, D., Rambaut, A., 2012. Bayesian phylogenetics with BEAUti and the BEAST 1.7. Mol. Biol. Evol. 29, 1969-1973.

Durant, D., Fritz, H., Blais, S., Duncan, P., 2003. The functional response in three species of herbivorous Anatidae: effects of sward height, body mass and bill size. J. Anim. Ecol. 72, 220-231.

Ellegren, H., Smeds, L., Burri, R., Olason, P.I., Backström, N., Kawakami, T., Kunstner A., Makinen, H., Nadachowska-Brzyska, K., Qvarnström, A., Uebbing, S., Wolf, J.B. W., 2012. The genomic landscape of species divergence in Ficedula flycatchers. Advance online publication.

Fox, A.D., Bergersen, L., 2005. Lack of competition between barnacle geese Branta leucopsis and pink-footed geese Anser brachyrhynchus during the pre-breeding period in Svalbard. J. Avian Biol. 36, 173-178.

Frantz, L., 2015. Speciation and Domestication in Suiformes: A Genomic Perspective. Wageningen University, Wageningen.

Frantz, L.A.F., Schraiber, J.G., Madsen, O., Megens, H.J., Bosse, M., Paudel, Y., Semiadi, G., Meijaard, E., Li, N., Crooijmans, R.P.M.A., Archibald, A.L., Slatkin, M., Schook, L.B., Larson, G., Groenen, M.A.M., 2013. Genome sequencing reveals fine scale diversification and reticulation history during speciation in Sus. Genome Biol. 14

Fulton, T.L., Letts, B., Shapiro, B., 2012. Multiple losses of flight and recent speciation in steamer ducks. Proc. Roy. Soc. B-Biol. Sci. 279, 2339-2346.

Gil, F., Donsker, D., 2013. IOC World Bird List (v 3.3). Available at <http:// www.worldbirdnames.org>.

Giroux, J.F., Bergeron, R., 1996. Spring diets of sympatric Greater Snow Geese and Canada Geese in southern Quebec. Can. J. Zool. 74, 950-953.

Gonzalez, J., Duttmann, H., Wink, M., 2009. Phylogenetic relationships based on two mitochondrial genes and hybridization patterns in Anatidae. J. Zool. 279, 310 318.

Graybeal, A., 1998. Is it better to add taxa or characters to a difficult phylogenetic problem? Syst. Biol. 47, 9-17.

Heuermann, N., van Langevelde, F., van Wieren, S.E., Prins, H.H., 2011. Increased searching and handling effort in tall swards lead to a Type IV functional response in small grazing herbivores. Oecologia 166, 659-669.

Huang, Y.H., Li, Y.R., Burt, D.W., Chen, H.L., Zhang, Y., Qian, W.B., Kim, H., Gan, S.Q. Zhao, Y.Q., Li, J.W., Yi, K., Feng, H.P., Zhu, P.Y., Li, B., Liu, Q.Y., Fairley, S., Magor, K. E., Du, Z.L., Hu, X.X., Goodman, L., Tafer, H., Vignal, A., Lee, T., Kim, K.W., Sheng, Z Y. An, Y., Searle, S., Herrero, J., Groenen, M.A.M. Crooijmans, R.P.M.A., Faraut, T. Cai, Q.L., Webster, R.G., Aldridge, J.R., Warren, W.C., Bartschat, S., Kehr, S., Marz, M., Stadler, P.F., Smith, J., Kraus, R.H.S., Zhao, Y.F., Ren, L.M., Fei, J., Morisson, M. Kaiser, P., Griffin, D.K., Rao, M., Pitel, F., Wang, J., Li, N., 2013. The duck genome and transcriptome provide insight into an avian influenza virus reservoir species. Nat. Genet. 45, 776-783.

Humphries, E.M., Peters, J.L., Jonsson, J.E., Stone, R., Afton, A.D., Omland, K.E., 2009 Genetic differentiation between sympatric and allopatric wintering populations of snow geese. Wilson J. Ornithol. 121, 730-738.

Hung, C.M., Drovetski, S.V., Zink, R.M., 2012. Multilocus coalescence analyses support a mtDNA-based phylogeographic history for a widespread palearctic passerine bird, sitta Europaea. Evolution 66, 2850-2864.

Ilves, K.L., Lopez-Fernandez, H., 2014. A targeted next-generation sequencing toolkit for exon-based cichlid phylogenomics. Mol. Ecol. Resour. 14, 802-811.

Innan, H., Watanabe, H., 2006. The effect of gene flow on the coalescent time in the human-chimpanzee ancestral population. Mol. Biol. Evol. 23, 1040-1047.

Jarvis, E.D., Mirarab, S., Aberer, A.J., Li, B., Houde, P., Li, C., Ho, S.Y.W., Faircloth, B.C., Nabholz, B., Howard, J.T., Suh, A., Weber, C.C., da Fonseca, R.R., Li, J.W., Zhang, F. Li, H., Zhou, L., Narula, N., Liu, L., Ganapathy, G., Boussau, B., Bayzid, M.S. Zavidovych, V., Subramanian, S., Gabaldon, T., Capella-Gutierrez, S., HuertaCepas, J., Rekepalli, B., Munch, K., Schierup, M., Lindow, B., Warren, W.C., Ray, D., Green, R.E., Bruford, M.W., Zhan, X.J., Dixon, A., Li, S.B., Li, N., Huang, Y.H., Derryberry, E.P., Bertelsen, M.F., Sheldon, F.H., Brumfield, R.T., Mello, C.V., Lovell, P.V., Wirthlin, M., Schneider, M.P.C., Prosdocimi, F., Samaniego, J.A., Velazquez, A.M.V., Alfaro-Nunez, A., Campos, P.F., Petersen, B., Sicheritz-Ponten, T., Pas, A Bailey, T., Scofield, P., Bunce, M., Lambert, D.M., Zhou, Q., Perelman, P., Driskell, A.C., Shapiro, B., Xiong, Z.J., Zeng, Y.L., Liu, S.P., Li, Z.Y., Liu, B.H., Wu, K., Xiao, J. Yinqi, X., Zheng, Q.M., Zhang, Y., Yang, H.M., Wang, J., Smeds, L., Rheindt, F.E.
Braun, M., Fjeldsa, J., Orlando, L., Barker, F.K., Jonsson, K.A., Johnson, W., Koepfli, K.P., O'Brien, S., Haussler, D., Ryder, O.A., Rahbek, C., Willerslev, E., Graves, G.R. Glenn, T.C., McCormack, J., Burt, D., Ellegren, H., Alstrom, P., Edwards, S.V. Stamatakis, A., Mindell, D.P., Cracraft, J., Braun, E.L., Warnow, T., Jun, W., Gilbert, M.T.P., Zhang, G.J., 2014. Whole-genome analyses resolve early branches in the tree of life of modern birds. Science 346, 1320-1331.

Jetz, W., Thomas, G.H., Joy, J.B., Hartmann, K., Mooers, A.O., 2012. The global diversity of birds in space and time. Nature 491, 444-448.

Jiang, F.W., Miao, Y.W., Liang, W., Ye, H.Y., Liu, H.L., Liu, B., 2010. The complete mitochondrial genomes of the whistling duck (Dendrocygna javanica) and black swan (Cygnus atratus): dating evolutionary divergence in Galloanserae. Mol. Biol. Rep. 37, 3001-3015.

Jonker, R.M., Kraus, R.H.S., Zhang, Q., Van Hooft, P., Larsson, K., Van der Jeugd, H.P., Kurvers, R.H.J.M., Van Wieren, S.E., Loonen, M.J.J.E., Crooijmans, R.P.M.A., Ydenberg, R.C., Groenen, M.A.M., Prins, H.H.T., 2013. Genetic consequences of breaking migratory traditions in barnacle geese Branta leucopsis. Mol. Ecol. 22, 5835-5847.

Kahlke, R.D., 2014. The origin of Eurasian Mammoth Faunas (MammuthusCoelodonta Faunal Complex). Quat. Sci Rev. 96, 32-49.

Kerr, K.C.R., Cloutier, A., Baker, A.J., 2014. One hundred new universal exonic markers for birds developed from a genomic pipeline. J. Ornithol. 155, 561-569.

Kingman, J.F.C., 1980. Mathematics of Genetic Diversity. Society for Industrial and Applied Mathematics, Philadelphia, Pa.

Knowles, L.L., 2009. Estimating species trees: methods of phylogenetic analysis when there is incongruence across genes. Syst. Biol. 58, 463-467.

Knowles, L.L., Kubatko, L.S., 2010. Estimating Species Trees: Practical and Theoretical Aspects. Wiley-Blackwell, Hobroken, NJ.

Kraus, R.H.S., Kerstens, H.H.D., van Hooft, P., Megens, H.J., Elmberg, J., Tsvey, A., Sartakov, D., Soloviev, S.A., Crooijmans, R.P.M.A., Groenen, M.A.M., Ydenberg, R. C., Prins, H.H.T., 2012. Widespread horizontal genomic exchange does not erode species barriers among sympatric ducks. BMC Evol. Biol., 12

Kubatko, L.S., Carstens, B.C., Knowles, L.L., 2009. STEM: species tree estimation using maximum likelihood for gene trees under coalescence. Bioinformatics 25, 971 973.

Lavretsky, P., McCracken, K.G., Peters, J.L., 2014. Phylogenetics of a recent radiation in the mallards and allies (Ayes: Anas): inferences from a genomic transect and the multispecies coalescent. Mol. Phylogenet. Evol. 70, 402-411.

Lee, S.Y., Scott, G.R., Milsom, W.K., 2008. Have wing morphology or flight kinematics evolved for extreme high altitude migration in the bar-headed goose? Comp. Biochem. Phys. C 148, 324-331.

Li, H., Durbin, R., 2009. Fast and accurate short read alignment with BurrowsWheeler transform. Bioinformatics 25, 1754-1760.

Liu, K., Linder, C.R., Warnow, T., 2010. Multiple sequence alignment: a major challenge to large-scale phylogenetics. PLoS Curr. 2, RRN1198.

Liu, L., Wu, S.Y., Yu, L.L., 2015. Coalescent methods for estimating species trees from phylogenomic data. J. Syst. Evol. 53, 380-390.

Livezey, B.C., 1996. A phylogenetic analysis of geese and swans (Anseriformes: Anserinae), including selected fossil species. Syst. Biol. 45, 415-450.

Lu, L., Chen, Y., Wang, Z., Li, X., Chen, W., Tao, Z., Shen, J., Tian, Y., Wang, D., Li, G., 2015. The goose genome sequence leads to insights into the evolution of waterfowl and susceptibility to fatty liver. Genome Biol. 16, 89.

Macdonald, G.A., Abbott, A.T., Peterson, F.L., 1983. Volcanoes in the Sea: The Geology of Hawaii. University of Hawaii Press.

Maddison, W.P., 1997. Gene trees in species trees. Syst. Biol. 46, 523-536.

Martin, P.S., Klein, R.G., 1989. Quaternary Extinctions: A Prehistoric Revolution. University of Arizona Press.

Mooij, J., Zöckler, C., 1999. Reflections on the systematics, distribution and status of Anser fabalis (Latham, 1787). Casarca 5, 103-120.

Nater, A., Burri, R., Kawakami, T., Smeds, L., Ellegren, H., 2015. Resolving evolutionary relationships in closely related species with whole-genome sequencing data. Syst. Biol. 64, 1000-1017.

Ottenburghs, J., Ydenberg, R.C., Van Hooft, P., Van Wieren, S.E., Prins, H.H.T., 2015 The Avian Hybrids Project: gathering the scientific literature on avian hybridization. Ibis 157, 892-894.

Ottenburghs, J., van Hooft, P., van Wieren, S.E., Ydenberg, R.C., Prins, H.H.T., 2016 Hybridization in geese: a review. Front. Zool. 13, 1-9.

Owen, M., 1976. Factors affecting the distribution of geese in the British Isles. Wildfowl 27, 143-147.

Owen, M., 1980. Wild Geese of the World: Their Life History and Ecology. Batsford, London.

Pamilo, P., Nei, M., 1988. Relationships between Gene Trees and Species Trees. Mol. Biol. Evol. 5, 568-583.

Parham, J.F., Donoghue, P.C.J., Bell, C.J., Calway, T.D., Head, J.J., Holroyd, P.A., Inoue, J. G., Irmis, R.B., Joyce, W.G., Ksepka, D.T., Patane, J.S.L., Smith, N.D., Tarver, J.E., van Tuinen, M., Yang, Z.H., Angielczyk, K.D., Greenwood, J.M., Hipsley, C.A., Jacobs, L., Makovicky, P.J., Muller, J., Smith, K.T., Theodor, J.M., Warnock, R.C.M., Benton, M. ., 2012. Best practices for justifying fossil calibrations. Syst. Biol. 61, 346-359.

Paxinos, E.E. James, H.F. Olson, S.L., Sorenson, M.D., Jackson, J., Fleischer, R.C., 2002 MtDNA from fossils reveals a radiation of Hawaiian geese recently derived from the Canada goose (Branta canadensis). Proc. Natl. Acad. Sci. U. S. A. 99, 13991404.

Payseur, B.A., 2010. Using differential introgression in hybrid zones to identify genomic regions involved in speciation. Mol. Ecol. Resour. 10, 806-820.

Pereira, S.L., Baker, A.J., 2006. A mitogenomic timescale for birds detects variable phylogenetic rates of molecular evolution and refutes the standard molecular clock. Mol. Biol. Evol. 23, 1731-1740. 
Prins, H.H.T., 1998. The origins and development of grassland communities in northwestern Europe. In: Wallis de Vries, M.F., Bakker, J.P., van Wieren, S.E. (Eds.), Grazing and Conservation Management. Kluwer Academic Publishers, Boston, pp. 55-105

Prum, R.O., Berv, J.S., Dornburg, A., Field, D.J., Townsend, J.P., Lemmon, E.M., Lemmon, A.R., 2015. A Comprehensive Phylogeny of Birds (Aves) Using Targeted Next-Generation DNA Sequencing. Advance online publication.

Quinn, T., 1992. The genetic legacy of Mother Goose-phylogeographic patterns of lesser snow goose Chen caerulescens caerulescens maternal lineages. Mol. Ecol. $1,105-117$.

Quinn, T.W., Shields, G.F., Wilson, A.C., 1991. Affinities of the Hawaiian Goose Based on 2 Types of Mitochondrial-DNA Data. Auk 108, 585-593.

Randler, C., 2008. Hybrid wildfowl in Central Europe - an overview. Waterbirds 31, 143-146.

Rannala, B., Yang, Z.H., 2003. Bayes estimation of species divergence times and ancestral population sizes using DNA sequences from multiple loci. Genetics 164, 1645-1656.

Ranwez, V., Delsuc, F., Ranwez, S., Belkhir, K., Tilak, M.K., Douzery, E.J.P., 2007. OrthoMaM: a database of orthologous genomic markers for placental mammal phylogenetics. BMC Evol. Biol., 7

Reed, A., 1976. Geese, nutrition and farmland. Wildfowl 27, 153-155.

Rheindt, F.E., Edwards, S.V., 2011. Genetic introgression: an integral but neglected component of speciation in birds. Auk 128, 620-632.

Rodway, M.S., 2007. Timing of pairing in waterfowl I: Reviewing the data and extending the theory. Waterbirds 30, 488-505.

Rokas, A., Williams, B.L. King, N., Carroll, S.B., 2003. Genome-scale approaches to resolving incongruence in molecular phylogenies. Nature 425, 798-804.

Ruokonen, M., Aarvak, T., Madsen, J., 2005. Colonization history of the high-arctic pink-footed goose Anser brachyrhynchus. Mol. Ecol. 14, 171-178.

Ruokonen, M., Kvist, L., Lumme, J., 2000. Close relatedness between mitochondrial DNA from seven Anser goose species. J. Evol. Biol. 13, 532-540.

Ruokonen, M., Litvin, K., Aarvak, T., 2008. Taxonomy of the bean goose-pink-footed goose. Mol. Phylogenet. Evol. 48, 554-562.

Sangster, G., Oreel, G.J., 1996. Progress in taxonomy of taiga and tundra bean geese. Dutch Birding 18, 310-316.

Schluter, D., 2000. The Ecology of Adaptive Radiation. Oxford University Press.

Scribner, K.T., Talbot, S.L., Pearce, J.M., Pierson, B.J., Bollinger, K.S., Derksen, D.V., 2003. Phylogeography of Canada Geese (Branta canadensis) in western North America. Auk 120, 889-907.
Shields, G.F., 1990. Analysis of Mitochondrial-DNA of Pacific Black Brant (BrantaBernicla-Nigricans). Auk 107, 620-623.

Shields, G.F., Wilson, A.C., 1987. Calibration of Mitochondrial-DNA Evolution in Geese. J. Mol. Evol. 24, 212-217.

Smith, N.A., 2015. Sixteen vetted fossil calibrations for divergence dating of Charadriiformes (Aves, Neognathae). Palaeontol Electr., 18

Stamatakis, A., 2006. RAxML-VI-HPC: maximum likelihood-based phylogenetic analyses with thousands of taxa and mixed models. Bioinformatics 22, 26882690.

Toews, D.P.L., Brelsford, A., 2012. The biogeography of mitochondrial and nuclear discordance in animals. Mol. Ecol. 21, 3907-3930.

van Tuinen, M., Hedges, S.B., 2001. Calibration of avian molecular clocks. Mol. Biol. Evol. 18, 206-213.

Van Wagner, C.E., Baker, A.J., 1990. Association between Mitochondrial-DNA and Morphological Evolution in Canada Geese. J. Mol. Evol. 31, 373-382.

Volkovsky, D., Kulikova, I., Gerasimov, Y.N., Zhuravlev, Y.N., 2013. Genetic diversity of Anser albifrons Scopoli, 1769 and Anser fabalis Latham, 1787 in the Russian Far East. Russ. J. Genet+ 49, 428-440.

Wall, J.D., 2003. Estimating ancestral population sizes and divergence times. Genetics 163, 395-404.

Weir, J.T., Schluter, D., 2008. Calibrating the avian molecular clock. Mol. Ecol. 17, 2321-2328.

Wetmore, A., 1956. A Check-List of the Fossil and Prehistoric Birds of North America and the West Indies. Smithsonian Institution.

Wu, Y.F., 2012. Coalescent-based species tree inference from gene tree topologies under incomplete lineage sorting by maximum likelihood. Evolution 66, 763775.

Yang, Z., Goldman, N., Friday, A., 1994. Comparison of models for nucleotide substitution used in maximum-likelihood phylogenetic estimation. Mol. Biol. Evol. 11, 316-324.

Yang, Z.H., 2007. PAML 4: phylogenetic analysis by maximum likelihood. Mol. Biol. Evol. 24, 1586-1591.

Zachos, J., Pagani, M., Sloan, L., Thomas, E., Billups, K., 2001. Trends, rhythms, and aberrations in global climate $65 \mathrm{Ma}$ to present. Science 292, 686-693.

Zhang, Y., Jia, Q., Prins, H.H., Cao, L., de Boer, W.F., 2015. Individual-Area Relationship Best Explains Goose Species Density in Wetlands. 